\title{
Passive uptake in the small intestine and active uptake in the hindgut contribute to the highly efficient mineral metabolism of the common mole-rat, Cryptomys hottentotus
}

\author{
BY TAMMY PITCHER AND ROCHELLE BUFFENSTEIN \\ Physiology Department, Medical School of the University of the Witwatersrand, 7 York Road, \\ Parktown, 2193, South Africa
}

(Received 1 March 1993 - Revised 9 June 1993 - Accepted 2 July 1993)

\begin{abstract}
Cryptomys hottentotus has no access to dietary or endogenous sources of cholecalciferol $\left(\mathrm{D}_{3}\right)$. Serum concentrations of calcifediol $\left(25(\mathrm{OH}) \mathrm{D}_{3}\right)$ were undetectable $(<5 \mathrm{ng} / \mathrm{ml})$ and calcitriol $\left(1,25(\mathrm{OH})_{2} \mathrm{D}_{3}\right)$, although detectable in plasma, was at a low concentration $(31.40(\mathrm{SEM} \mathrm{3.06} \mathrm{pg/ml).} \mathrm{Despite} \mathrm{their}$ naturally impoverished vitamin $D$ status, these animals exhibited highly efficient mineral absorption processes (Ca apparent fractional absorption efficiency, AFA (\%) 95.33 (SEM 1.36); inorganic $P\left(P_{i}\right)$ AFA (\%) 93.49 (SEM 0.81)). Furthermore, plasma mineral content was tightly regulated (Ca 2.57 (SEM 0.08) mmol/l; Mg 1.23 (SEM 0.05) mmol/l; $P_{\mathrm{i}} 2.12$ (SEM 0.15) $\mathrm{mmol} / \mathrm{l}$ ). Mode of uptake in $C$. hottentotus was unlike that in other $\mathrm{D}_{3}$-replete mammals. First, passive (rather than active) uptake occurred in the traditional site of active $C a$ absorption (with serosal:mucosal (S:M) ratios in the duodenum of 1.32 (SEM 0.13)), and the only site of active Ca uptake was the hindgut (caecum S:M 3.35 (SEM 0.46); proximal colon S: M 2.13 (SEM 0-30)). Despite the presence of active uptake in these hindgut regions, their overall contribution to the daily rate of mineral absorption was small ( 9.53 (SEM 1.27) \%). These underground inhabitants rely upon highly efficient, passive mineral uptake. This is adequate to meet their mineral requirements and maintain mineral homeostasis in the absence of vitamin $D$.
\end{abstract}

Mineral metabolism: Calcium: Mole-rat

The common mole-rat, Cryptomys hottentotus (order Rodentia; family Bathyergidae), lives underground in an extensive maze of tightly plugged burrows, in the mesic areas of southern and central Africa (de Graaff, 1981). Given their strictly subterranean, chthonic habitat and herbivorous diet, these animals have no obvious natural source of cholecalciferol $\left(\mathrm{D}_{3}\right)$. In addition, Ca requirements in mole-rats are high as their large, evergrowing incisors are continually worn down during burrow excavations and replaced. It is speculated, therefore, that the common mole-rat is deficient in $\mathrm{D}_{3}$ and might meet its mineral requirements in a unique $\mathrm{D}_{3}$-independent manner. Furthermore, as this animal is a hindgut fermenter, the site of nutrient absorption might be lower down the gut than commonly reported (duodenum).

Previous mineral studies that addressed the problem of mineral metabolism in chthonic inhabitants (Cryptomys damarensis, Skinner et al. 1991; Pitcher et al. 1992, and Heterocephalus glaber, Buffenstein \& Yahav, $1991 \mathrm{a}$ ) indicate that dietary Ca absorption is mediated through highly efficient non-saturable processes. These chthonic species absorbed more than $85 \%$ of the available $\mathrm{Ca}$ in their diet (Buffenstein \& Yahav, 1991 a; Skinner et al. 1991; Pitcher et al. 1992), whereas the efficiency of most other mammals is below $60 \%$ (Brommage \& Baxter, 1988a; Hughes, 1988). It is not known whether these characteristics are typical of all subterranean mammals. Furthermore, the mechanisms employed are not fully understood. We addressed these questions first by monitoring mineral homeostasis in 
freshly caught $C$. hottentotus, fed a diet similar in Ca content to their natural diet, then by examining the mode of $\mathrm{Ca}$ uptake along the entire length of the gastrointestinal tract (GIT).

\section{MATERIALS AND METHODS \\ Animals and management}

Freshly caught male and female adult animals (112.89 (SEM 12.05) g) were used in this study. Animals were trapped on the Witwatersrand, Johannesburg, South Africa. Thereafter, they were housed in the Central Animal Unit (University of the Witwatersrand Medical School) under constant climatic conditions (ambient temperature $26 \pm 2^{\circ}$ and humidity $60 \%$ ) in a darkened room supplied with a single incandescent $(40 \mathrm{~W})$ light bulb. They were kept in colonies in glass terraria and transparent perspex burrow systems which were partially filled with vermiculite. Before experimentation, all animals were given an $a d$. lib. diet of sweet potato (Ipomoea batatus) and apple. Mole-rats adapted well to captivity, remaining healthy and maintaining body mass.

\section{Experimental treatment}

The animals were placed on a diet of sweet potato (containing $(\mathrm{mg} / \mathrm{g}) \mathrm{Ca} 1 \cdot 7$, inorganic $\mathrm{P}$ ( $\left.\mathrm{P}_{\mathrm{i}}\right) 2.9$, water $753 ; 15.84 \mathrm{~kJ} / \mathrm{g}$ dry weight) and apple (containing $\left(\mathrm{mg} / \mathrm{g}\right.$ ) Ca $0.5, \mathrm{P}_{\mathrm{i}} 0.8$, water $855 ; 16.43 \mathrm{~kJ} / \mathrm{g}$ dry weight) for at least 4 weeks before experimentation, to enable the gut microfauna to adapt (if need be) to the change in diet (Buffenstein \& Yahav, 1991b). During the experimental period they were housed individually in metabolic cages (Techniplast, Johannesburg), facilitating the measurement of mineral balance and collection of leftover food and of urine and faeces. The quantity of food eaten and urine and faeces produced was monitored over an $11 \mathrm{~d}$ period.

Representative food samples, uneaten food, and faeces were weighed and dried to a constant weight. Glass-fibre filter papers (Whatman GF/D) were placed over the openings of the urine collection tubes to prevent contamination. Urine was collected under light liquid paraffin and measured to an accuracy of $0.1 \mathrm{ml}$. A small drop of acetic acid was placed in each urine collection tube to prevent bacterial proliferation. Representative samples of urine were frozen at $-70^{\circ}$.

\section{Plasma and tissue collection}

All animals were anaesthetised with Sagatal $(30 \mathrm{mg} / \mathrm{kg})$. Thereafter, they were killed by cardiac exsanguination. Blood samples collected during this procedure were centrifuged and the plasma separated and frozen at $-70^{\circ}$ for later analyses.

Plasma analyses included measurement of $\mathrm{Ca}$ (ionized $\mathrm{Ca}\left(\mathrm{Ca}^{2+}\right)$ and total $\left.\mathrm{Ca}\right), \mathrm{P}_{\mathrm{i}}, \mathrm{Mg}$ and the vitamin $\mathrm{D}$ metabolites calcifediol $\left(25(\mathrm{OH}) \mathrm{D}_{3}\right)$ and calcitriol $\left(1,25(\mathrm{OH})_{2} \mathrm{D}_{3}\right)$.

Teeth and bones collected at the end of the experimental period were stored at $-20^{\circ}$ for later mineral analyses. The meat was removed from the bones by Dermestid beetles (courtesy of Mrs Lemma, SABS, Pretoria, South Africa). Bones were ashed overnight at $175^{\circ}$ and dissolved in $2 \mathrm{ml}$ concentrated $\mathrm{HCl}$.

\section{Vitamin $D$ metabolites}

Serum total $25(\mathrm{OH}) \mathrm{D}_{3}$ and $1,25(\mathrm{OH})_{2} \mathrm{D}_{3}$ metabolite concentrations were measured using the methods described by Haddad \& Chyu (1971) and Reinhardt et al. (1984) respectively. Before metabolite determination, plasma samples were subjected to extraction and purification techniques as described by Turnbull et al. (1982). The sensitivities of the $25(\mathrm{OH}) \mathrm{D}_{3}$ and $1,25(\mathrm{OH})_{2} \mathrm{D}_{3}$ assays were $5 \mathrm{ng} / \mathrm{ml}$ and $4 \mathrm{pg} / \mathrm{ml}$ serum respectively. 
Table 1. Body mass, food intake and food digestibility in the mole-rat (Cryptomys hottentotus) fed on sweet potato (Ipomoea batatus) and apple

Mean values with their standard errors for eight animals)

\begin{tabular}{lrr}
\hline & Mean & \multicolumn{1}{c}{ SEM } \\
\hline Body mass $(\mathrm{g})$ & 112.89 & 12.05 \\
Increase in body mass $(\% / 11 \mathrm{~d})$ & 8.09 & 2.56 \\
Food intake $(\mathrm{g}$ DM $/ 100 \mathrm{~g}$ body wt per d) & 8.20 & 0.68 \\
$\mathrm{AFA}(\%)$ & 95.33 & 1.36 \\
$\mathrm{Ca}$ & 93.49 & 0.81 \\
$\mathrm{P}_{\mathrm{i}}$ & & \\
$\mathrm{AFR}(\%)$ & 97.79 & 0.49 \\
$\mathrm{Ca}$ & 94.49 & 2.67 \\
$\mathrm{P}_{\mathrm{i}}$ & & \\
\hline
\end{tabular}

AFA, apparent fractional absorption; AFR, apparent fractional retention; $\mathrm{P}_{\mathrm{i}}$, inorganic phosphorus.

\section{Mineral analyses}

$\mathrm{Ca}$ and $\mathrm{Mg}$ in plasma, food, faeces, urine, bone and teeth was determined in a solution of $\mathrm{LaCl}_{3}(2 \mathrm{~g} \mathrm{La} / 1)$ by atomic absorption spectrophotometry (Varian Spectra 10). $\mathbf{P}_{1}$ was assayed colorimetrically using a commercially available kit based on the method of Hurst (1967) and Kraml (1966). Apparent fractional absorption (AFA) was calculated as

$$
\mathrm{AFA}=\frac{(X \text { ingested } / \mathrm{d})-(X \text { in faeces } / \mathrm{d})}{(X \text { ingested } / \mathrm{d})} \times 100
$$

where $X$ is $\mathrm{Ca}, \mathrm{P}_{\mathrm{i}}$ or $\mathrm{Mg}$. The apparent fractional retention (AFR) was similarly calculated

$$
\operatorname{AFR}=\frac{(X \text { absorbed } / \mathrm{d})-(X \text { in urine } / \mathrm{d})}{(X \text { absorbed } / \mathrm{d})} \times 100
$$

where $X$ is $\mathrm{Ca}, \mathrm{P}_{\mathrm{i}}$ or $\mathrm{Mg}$.

\section{Alkaline phosphatase}

Plasma alkaline phosphatase $(E C$ 3 1.3 .1$)$ was assayed colorimetrically (Timepac alk phos reagent; Technicon No: T40-0009), based on the methods described by Morgenstein et al. (1965).

\section{Mode of calcium uptake}

On completion of the mineral balance study, mode of uptake of Ca was determined using a modified everted gut sac technique (as described by Wilson \& Wiseman, 1954). Briefly, mole-rats were anaesthetised with Sagatal $(30 \mathrm{mg} / \mathrm{kg})$ and an incision made along the ventral midline. Thereafter, the intestine was carefully excised and placed into a welloxygenated $\left(\mathrm{O}_{2}-\mathrm{CO}_{2} ; 95: 5 ; \mathrm{v} / \mathrm{v}\right)$ storage solution $(146 \mathrm{~mm}-\mathrm{NaCl} ; 3.99 \mathrm{~mm}-\mathrm{KCl})$.

The intestine was divided into five sections: duodenum (i.e. from the pyloric sphincter to the ligament of Treitz), jejunum, proximal-, mid-, and distal ileal sections (Wilson \& Wiseman, 1954). In addition, the caecum, proximal- and distal colon were removed and thoroughly rinsed with the storage solution. Everted gut sacs of each of these sections were made using $30-35 \mathrm{~mm}$ lengths of intestine. They were filled with a known volume of buffered solution, comprising $151 \cdot 1 \mathrm{mM}-\mathrm{NaCl}, 20 \mathrm{~mm}-\mathrm{D}+$ glucose, $0 \cdot 299 \mathrm{~mm}-\mathrm{CaCl}_{2} \cdot 2 \mathrm{H}_{2} \mathrm{O}$, 


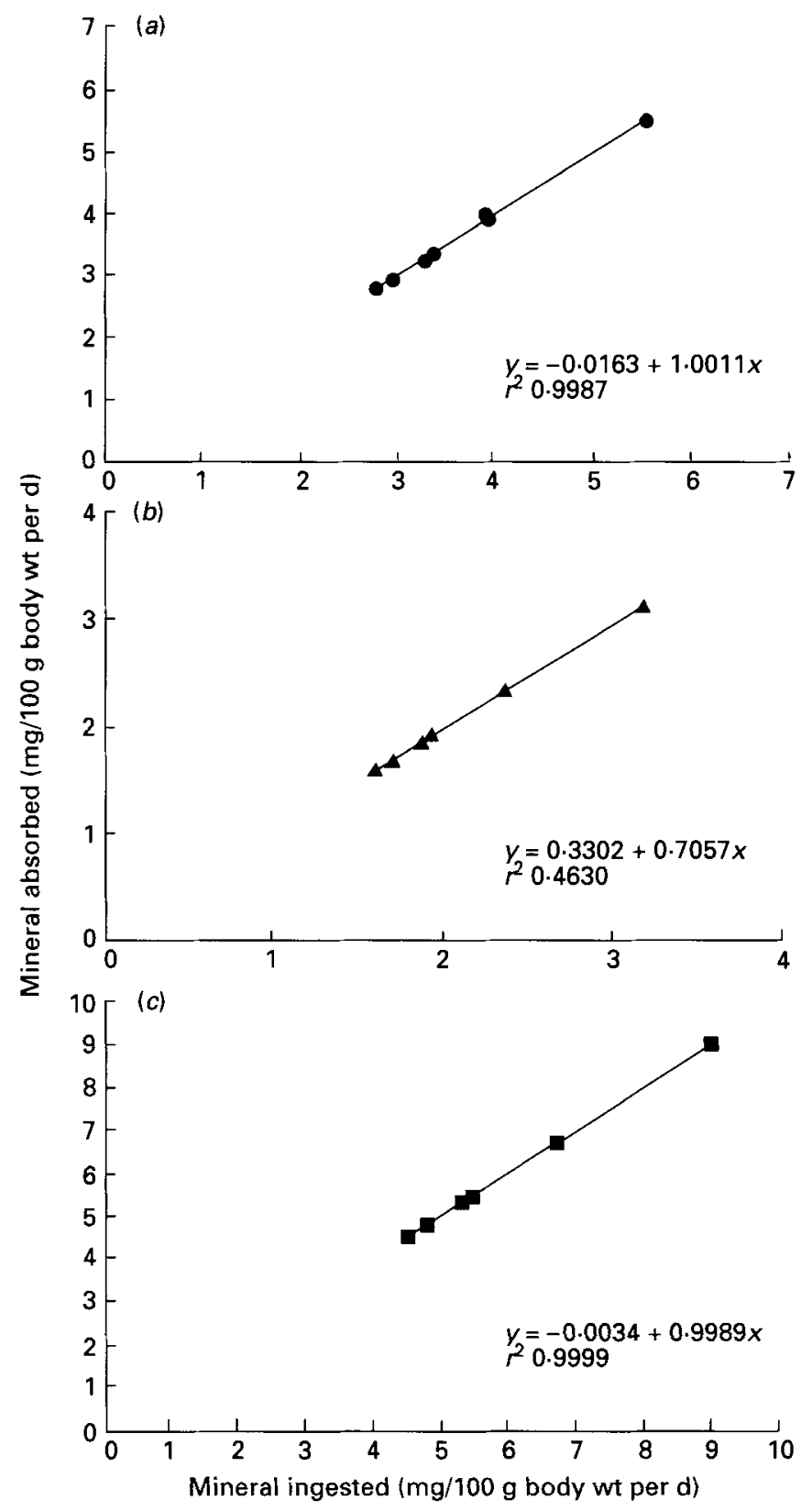

Fig. 1. Apparent absorption of $(a)$ calcium, $(b)$ magnesium and $(c)$ inorganic phosphorus by the mole-rat (C. hottentotus), showing direct dependence on the amount of mineral ingested. The points indicate individual animals $(n 8)$.

$3.219 \mathrm{~mm}^{-\mathrm{Na}_{2}} \mathrm{HPO}_{4}$ and $0.693 \mathrm{~mm}-\mathrm{NaH}_{2} \mathrm{PO}_{4} .2 \mathrm{H}_{2} \mathrm{O}$, to which ${ }^{45} \mathrm{Ca}$ (code no. CES 3; Amersham) was added. The intestinal sacs were incubated in the same buffer solution, and continually oxygenated $\left(\mathrm{O}_{2}-\mathrm{CO}_{2} ; 95: 5 ; \mathrm{v} / \mathrm{v}\right)$ for a period of $3 \mathrm{~h}$. Thereafter, the gut sacs were removed and the fluid inside the gut sacs drained into test tubes. Volume changes were measured and the concentration of ${ }^{45} \mathrm{Ca}$ was determined using a Packard Tri-carb (model 


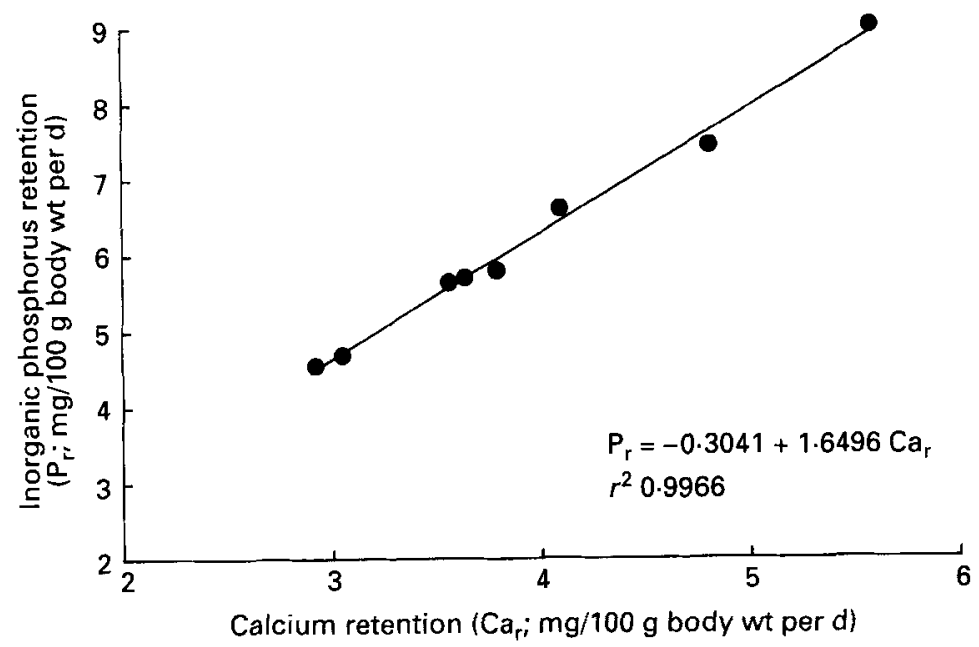

Fig. 2. The relationship between calcium retention and inorganic phosphorus retention for the mole-rat ( $C$. hottentotus). The points indicate individual animals $(n 8)$.

No. 300C) scintillation counter. All data, after correcting for volume changes, were expressed as the $\mathrm{S}: \mathrm{M}$ ratio, i.e. final concentration of ${ }^{45} \mathrm{Ca}$ inside the intestinal sac (serosal; $\mathrm{S}$ ): the concentration of ${ }^{45} \mathrm{Ca}$ outside the sac (mucosal; $\mathrm{M}$ ). S:M ratios $>1.5$ were considered indicative of active transport.

\section{Statistical analyses}

All data are expressed as means with their standard errors. Linear regression analyses were determined in accordance with the methods of Zar (1974).

\section{RESULTS}

Freshly caught experimental animals supplied with food ad. lib. gained about $0 \cdot 7 \%$ body weight/d over the $11 \mathrm{~d}$ experimental period (Table 1).

\section{Mineral balance}

The AFA (\%) of $\mathrm{Ca}$ and $\mathrm{P}_{\mathrm{i}}$ for the sweet potato and apple was exceptionally high (Table 1), with a significant correlation between the amount ingested and the amount absorbed for $\mathrm{Ca}, \mathrm{Mg}$ and $\mathrm{P}_{\mathrm{i}}$ (Fig. 1). There was, however, no correlation between the amount of each element absorbed and the amount excreted in the urine.

Mineral balance was in a state of positive flux for both elements, with Ca showing the higher AFR and that of $\mathrm{P}_{\mathrm{i}}$ being approximately $3 \%$ less (Table 1 ). A highly significant $(P<0.001)$ linear relationship existed between $\mathrm{Ca}$ retention and $\mathrm{P}_{\mathrm{i}}$ retention (Fig. 2).

Bone and teeth mineral data show that there was significantly more $\mathrm{Ca}$ and $\mathrm{P}_{\mathrm{i}}$ present in the teeth (per $\mathrm{mm}$ ) of $C$. hottentotus than in the bones (Table 2). Teeth have an average length of $16 \cdot 17 \pm 0 \cdot 64 \mathrm{~mm}$.

\section{Plasma mineral and $D_{3}$ metabolite concentrations}

Plasma $25(\mathrm{OH}) \mathrm{D}_{3}$ levels were below the sensitivity of the assay $(<5 \mathrm{ng} / \mathrm{ml}$; Table 3$)$, whereas $1,25(\mathrm{OH})_{2} \mathrm{D}_{3}$ was present (Table 3). Plasma mineral concentrations were tightly regulated and within the normal range for mammals (Table 3 ). 
Table 2. Length of teeth and mineral contents of teeth and bones from the mole-rat (Cryptomys hottentotus)

(Mean values with their standard errors for eight animals)

\begin{tabular}{|c|c|c|c|c|c|}
\hline & & \multicolumn{2}{|c|}{ Teeth } & \multicolumn{2}{|c|}{ Long bones } \\
\hline & & Mean & SEM & Mean & SEM \\
\hline & Length (mm) & $16 \cdot 17$ & 0.64 & & \\
\hline & $\mathrm{Ca}(\mathrm{mmol} / \mathrm{g})$ & $4 \cdot 58$ & 0.36 & $2 \cdot 40$ & 0.07 \\
\hline & $\mathrm{P}_{\mathrm{i}}(\mathrm{mmol} / \mathrm{g})$ & $3 \cdot 32$ & 0.25 & $2 \cdot 20$ & 0.43 \\
\hline
\end{tabular}

$\mathbf{P}_{\mathrm{i}}$, inorganic phosphorus.

Table 3. Plasma mineral and vitamin D metabolite concentrations of the mole-rat (Cryptomys hottentotus)

(Mean values with their standard errors for eight animals)

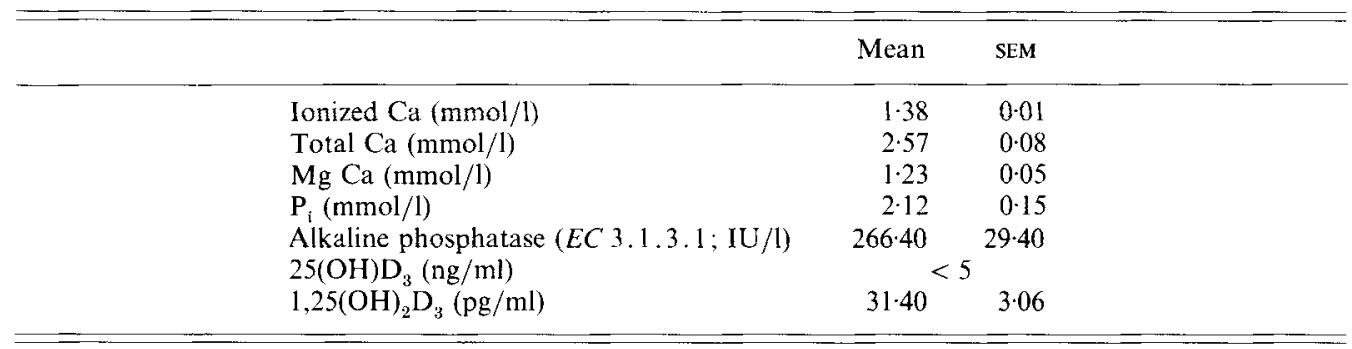

$P_{i}$, inorganic phosphorus.

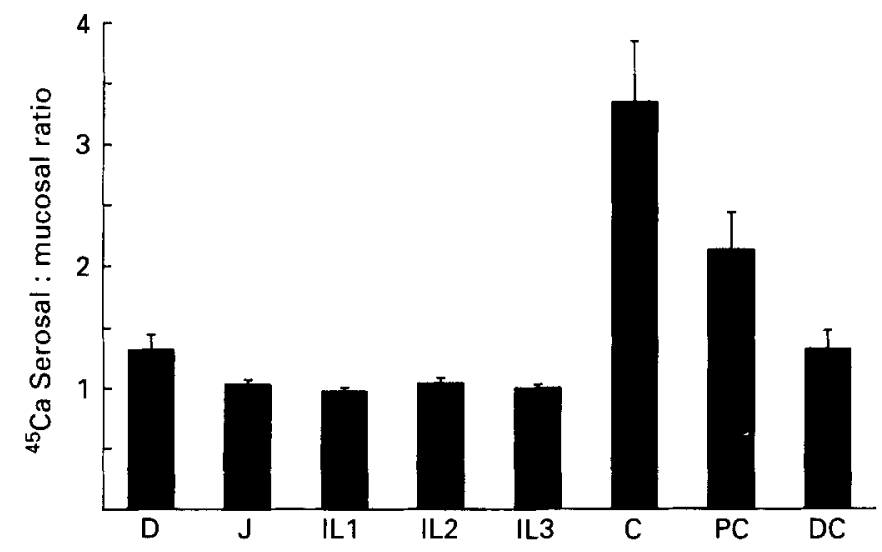

Fig. 3. Serosal:mucosal (S:M) ratios as indicators of active and passive transport along the entire gastrointestinal tract of the mole-rat (C. hontentotus). D, duodenum; J, jejunum; ILI, ileal segment 1 ; IL2, ileal segment 2; IL3, ileal segment 3 ; C, caecum; PC, proximal colon; DC, distal colon. S:M $>1.5$ indicates active uptake; S:M $<1.5$ indicates passive uptake. Values are means with their standard errors.

\section{${ }^{45}$ Ca uptake}

Active uptake of ${ }^{45} \mathrm{Ca}$ in $C$. hottentotus occurred in the hindgut only (caecum S:M 3.35 (SEM 0.46); proximal colon S:M 2.13 (SEM 0.30)), whereas along the entire length of the small intestine the uptake of ${ }^{45} \mathrm{Ca}$ was passive (duodenum S:M 1.32 (SEM 0.13); Fig. 3). 


\section{DISCUSSION}

Mineral homeostasis (Table 1) and vitamin D status (Table 3) in C. hottentotus were similar to that of other mole-rat species (Buffenstein \& Yahav, 1991 a; Skinner et al. 1991; Pitcher et al. 1992), in that animals exhibited a positive net flux and highly efficient mineral absorption occurred despite an apparently impoverished vitamin D status. Furthermore, mode of uptake in the small intestine was similarly found to be passive (Fig. 3; Pitcher et al. 1992). This is, however, the first report to date of active uptake in the hindgut, rather than the traditional site of active Ca absorption, the duodenum.

\section{Plasma metabolites}

Serum levels of the principal circulating form of vitamin $\mathrm{D}\left(25(\mathrm{OH}) \mathrm{D}_{3}\right)$ are generally indicative of $\mathrm{D}_{3}$ status (Audran \& Kumar, 1985). An undetectable level of $25(\mathrm{OH}) \mathrm{D}_{3}$ (Table 3 ) in $C$. hottentotus suggests that these animals have an impoverished vitamin D status. Whilst the active metabolite is present (Table 3) in mole-rat plasma, it is in much lower amounts than that previously reported for other rodents (Clark et al. 1987). This again may reflect natural $\mathrm{D}_{3}$ deficiency. The low plasma concentrations present, however, appear sufficient to maintain normal plasma mineral concentrations (Table 3), a positive mineral flux (Table 1) and mineral homeostasis. The positive mineral balance is of no pathological consequence as excess mineral is deposited in the evergrowing and worn down teeth (Table 2).

Wild wood mice, bank voles (Shore et al. 1988) and horses also show detectable levels of $1,25(\mathrm{OH})_{2} \mathrm{D}_{3}$ in the absence of $25(\mathrm{OH}) \mathrm{D}_{3}$. It is suggested that they do not utilize vitamin D-mediated intestinal absorption (Horst et al. 1988). Rather, passive Ca absorption may prove sufficient for their mineral needs (Shore et al. 1988). This hypothesis, although untested and currently pure speculation, appears to hold true for $C$. hottentotus and other mole-rats, all of which maintain mineral homeostasis despite undetectable $25(\mathrm{OH}) \mathrm{D}_{3}$ concentrations (Buffenstein \& Yahav, 1991a; Pitcher et al. 1992; Skinner et al. 1991), and all of which show passive duodenal mineral absorption.

\section{Mineral homeostasis}

The AFA $(\%)$ of $C$. hottentotus parallels that of the other species of mole-rats studied to date, C. damarensis (Skinner et al. 1991; Pitcher et al. 1992) and H. glaber (Buffenstein \& Yahav, 1991 $a$ ), in that AFA exceeds $85 \%$. In this study, despite the observed apparent impoverished vitamin D status, absorption of Ca is extremely efficient (95.33 (SEM 1.36)\%), and is far higher than that previously reported in adult, non-breeding $\mathrm{D}_{3}$-replete mammals (30-70\%; Schaafsma et al. 1985; Brommage \& Baxter, 1988a; Silverberg, 1990). In addition, there is a significant correlation between the amount of each element ingested and the amount absorbed (Fig. 1). Mineral homeostasis appears, therefore, to occur via a highly efficient non-saturable mechanism. Similar non-saturable $\mathrm{D}_{3}$-independent modes of mineral uptake have been reported in rats in which unique demands are placed on both $\mathrm{Ca}$ homeostasis and skeletal metabolism (Dostal \& Toverud, 1984; Brommage \& Baxter, $1988 \mathrm{~b}$ ), and in other species of mole-rat studied to date (Buffenstein \& Yahav, 1991 $a$; Skinner et al. 1991; Pitcher et al. 1992).

There is no correlation between the amount of each element absorbed and the amount excreted in the urine; however, the retention of $\mathrm{P}_{\mathrm{i}}$ is closely correlated to Ca retention (Fig. 2; $P_{r}=-0.3041+1.6496 C a_{r}, r^{2} 0.9966 ;$ where $P_{r}$ and $C a_{r}$ are $P_{1}$ and $C a$ retention ( $\mathrm{mg} / 100 \mathrm{~g}$ body weight per $\mathrm{d}$ ) respectively). $\mathrm{P}_{\mathrm{i}}$ retention, like that of other hindgut fermenters (Braithwaite, 1975), appears, therefore, to be linked to that of Ca retention. Metabolism of $\mathrm{P}_{i}$ is closely related to Ca metabolism in $\mathrm{D}_{3}$-deficient animals, with a low- 
Ca diet resulting in an increase in parathyroid hormone (PTH) and a concomitant increase in urinary $\mathrm{P}_{\mathrm{i}}$ excretion (Braithwaite, 1975). This holds true for $C$. hottentotus, where $\mathrm{P}_{\mathrm{i}}$ AFR $(94.49 \%)$ was lower than that of $\mathrm{Ca}(97.79 \%)$.

An alternative explanation for the higher $\mathrm{P}_{1}$ urinary loss compared with $\mathrm{Ca}$ is afforded by the Ca: $\mathrm{P}_{\mathrm{i}}$ ratio of the teeth. The Ca: $\mathrm{P}_{\mathrm{i}}$ ratio for $C$. hottentotus teeth is 1.36 (SEM 0.06), which indicates that proportionately more $\mathrm{Ca}$ than $P_{i}$ is deposited in the teeth. This difference in the $\mathrm{Ca}: \mathrm{P}_{\mathrm{i}}$ ratio in the teeth may explain the greater loss of $\mathrm{P}_{\mathrm{i}}$ than $\mathrm{Ca}$ through urinary excretion (Table 1).

The $\mathrm{Ca}: \mathrm{P}_{\mathrm{i}}$ retention ratio in mole-rats was $1 \cdot 226$. This correlates well with the $\mathrm{Ca}: \mathrm{P}_{\mathrm{i}}$ ratio $(1: 1 \cdot 25)$ suggested by Thomas et al. (1988) as corresponding to the proportion of $\mathrm{Ca}$ and $\mathrm{P}_{\mathrm{i}}$ needed by rodents for whole body growth.

\section{Uptake of ${ }^{45} \mathrm{Ca}$ along the entire GIT}

$C$. hottentotus exhibited a most unusual mode of mineral uptake in the GIT, in that uptake was passive in the traditional site of active $\mathrm{Ca}$ absorption (the duodenum), and active in the hindgut, a region not normally associated with mineral absorption (Petith \& Schedl, 1976).

Active gastrointestinal uptake is regulated by vitamin D (Norman, 1990). Usually in the absence of $\mathrm{D}_{3}, \mathrm{Ca}$ uptake in the duodenum is passive and inadequate for normal physiological function. Young, vitamin D-deficient rats do not conform to this generalization, in that they may employ active uptake in the duodenum despite their deficient $\mathrm{D}_{3}$ status, but show no GIT active uptake elsewhere (Walling et al. 1974). Molerats, despite their $D_{3}$-deficient status, employ active mineral uptake in the caecum and proximal colon, sites not previously known to be involved with mineral uptake. Previous mole-rat studies in our laboratory did not examine the hindgut as a potential site for active $\mathrm{Ca}$ uptake. It is, therefore, possible that caecal active transport is used by all mole-rat species.

The employment of active transport in the hindgut, rather than the small intestine, might be an adaptation to the hindgut location of a fermentation chamber. Fermentation of fibre will liberate mineral previously trapped within the plant fibres. If this liberated mineral is to be retained in the body, it must be rapidly absorbed before faecal formation. Detection of active transport in the caecum could reflect vitamin D-mediated pathways at the low plasma concentrations of active hormone. Caecal function, and fermentation in particular, is influenced by vitamin D supplementation to mole-rats (Buffenstein \& Yahav, 1991b). This in turn implies that low hormonal levels may function in this region (a) to improve mineral uptake and (b) to assist in fermentative micro-organism proliferation and function, although caecal active uptake might be mediated by vitamin D-independent pathways.

The caecum and proximal colon show high $\mathrm{S}: \mathrm{M}$ ratios of 3.35 (SEM 0.46) and 2.13 (SEM 0.30) respectively, clearly indicative of active transport in these regions. The actual contribution of active transport to the total amount of mineral absorbed $(\mathrm{mg} / 100 \mathrm{~g}$ body weight per d) was determined by calculating the amount of $\mathrm{Ca}$ that is actively absorbed in the caecum and proximal colon, and correcting this to a daily rate. This was then compared with the total daily net fractional absorption. Active transport accounted for less than $10 \%$ of the net absorption. The majority of $\mathrm{Ca}$ absorbed must therefore occur via a nonsaturable, passive process. This hypothesis is supported by the consistently high mineral absorption efficiency data in the absence of vitamin D supplementation (Buffenstein \& Yahav, 1991 a; Skinner et al. 1991; Pitcher et al. 1992). Intestinal Ca absorption, although not apparently regulated by vitamin $\mathrm{D}$, is therefore obviously sufficient to maintain normal plasma homeostasis.

In hindgut fermenters, nutrients trapped within cell walls and fibre may be released only after fermentation in the caecum is complete. It is not known whether all hindgut 
fermenters, including man, increase absorption of nutrients in the hindgut if fed on a highfibre diet. Although most commercially important domestic animals are foregut fermenters and would therefore absorb nutrients adequately from the duodenum and not need this additional site for nutrient absorption, active absorption in the hindgut could be beneficial to non-ruminant herbivores e.g. horses (Schryver et al. 1970). It would be most advantageous for arid-adapted animals and animals eating a mineral-deficient diet to employ such a hindgut mechanism in order to extract fully most of the available nutrients and minerals.

In conclusion, $C$. hottentotus employs a different mode of mineral uptake to that of most mammals, with highly efficient passive transport in the duodenum and active uptake in the caecum and proximal hindgut. These regions of active mineral uptake are traditionally associated with symbiotic micro-organism fibre digestion. Employment of active transport here could act as a mineral trap. This would ensure that any mineral released during the fermentation process is absorbed for use by the animal, rather than lost in the faeces. It is most likely that caecal uptake plays a secondary role to passive duodenal transport, and merely facilitates the absorption of small quantities of mineral that have escaped prior absorption. Even in the absence of adequate amounts of vitamin D, passive transport is sufficient for mineral homeostasis.

The authors would like to thank Fraser Lamond for helping to trap and collect the molerats. The animals were housed and cared for by the Central Animal Unit of the University of the Witwatersrand, before experimentation. Thanks are also extended to $\mathrm{Mr}$ G. P. Moodley and Miss D. Zachen of the Mineral and Metabolism Research Unit, Baragwanath Hospital, who meticulously assisted in the analyses of samples. This work was approved by the animal ethics committee of the University of the Witwatersrand $(91 / 26 / 1)$.

\section{REFERENCES}

Audran, M. \& Kumar, R. (1985). The physiology and pathophysiology of vitamin D. Mayo Clinic Proceedings 60, 851-866.

Braithwaite, G. D. (1975). Studies on the absorption and retention of calcium and phosphorus by young and mature Ca-deficient sheep. British Journal of Nutrition 34, 311-324.

Brommage, R. \& Baxter, D. C. (1988a). Elevated calcium, phosphorus and magnesium retention in pregnant rats prior to the onset of fetal skeletal mineralization. Journal of Bone and Mineral Research 3, 667-672.

Brommage, R. \& Baxter, D. C. $(1988 b)$. Vitamin D-independent stimulation of intestinal calcium and phosphorus absorption during reproduction. Journal of Bone and Mineral Research 3, S156.

Buffenstein, R. \& Yahav, S. (1991 a). Cholecalciferol has no effect on calcium and inorganic phosphorus balance in a natural cholecalciferol-deplete subterranean mammal, the naked mole-rat (Heterocephalus glaber). Journal of Endocrinology 129, $21-26$.

Buffenstein, R. \& Yahav, S. (1991 b). The effect of diet on microfaunal population and function in the caecum of a subterranean mole-rat (Heterocephalus glaber). British Journal of Nutrition 65, 249-258.

Clark, S. A., Boass, A. \& Toverud, S. U. (1987). Effects of high dietary contents of calcium and phosphate in mineral metabolism and growth of vitamin D-deficient suckling and weaned rats. Bone and Mineral 2, 257-270.

De Graaff, G. (1981). The Rodents of Southern Africa: Notes on their Identification, Distribution, Ecology and Taxonomy. Pretoria: Butterworths.

Dostal, L. A. \& Toverud, S. U. (1984). Effect of vitamin $\mathrm{D}_{3}$ on duodenal calcium absorption in vivo during early development. American Journal of Physiology 246, G528-G534.

Haddad, J. G. \& Chyu, K. J. (1971). Competitive protein binding radioassay for 25-hydroxy cholecalciferol. Journal of Clinical Endocrinology and Metabolism 33, 992-995.

Horst, R. L., Koszewski, N. J. \& Reinhardt, T. A. (1988). Species variation of vitamin D metabolism and action: lessons to be learnt from farm animals. In Vitamin D. Molecular, Cellular and Clinical Endocrinology, pp. 93-101 [A. W. Norman, K. Schaefer, H. G. Grigolet and D. von Herrath, editors]. Berlin, Germany: Walter de Gruyter \& Co.

Hughes, B. D. (1988). Effect of lowering dietary calcium intake on fractional whole-body retention of calcium. 3 , S156. 
Hurst, R. O. (1967). A simplified approach to the use of determinants and calculation of rate equations for complex enzyme systems. Canadian Journal of Biochemistry 45, 2015-2016.

Morgenstein, S., Kessler, G., Auerback, J., Flow, R. V.\& Klein, B. (1965). An automated p-nitrophenylphosphate serum alkaline phosphatase procedure for the autoanalyser. Clinical Chemistry 11, 876-878.

Norman, A. W. (1990). Intestinal calcium absorption: a vitamin D hormone mediated adaptive response. American Journal of Clinical Nutrition 51, 290-300.

Petith, M. M. \& Schedl, H. P. (1976). Duodenal and ileal adaptation to dietary calcium restriction: in vivo studies in the rat. American Joumal of Physiology 231, 865-871.

Pitcher, T., Buffenstein, R., Keegan, J. D., Moodley, G. P.\& Yahav, S. (1992). Dietary calcium content, calcium balance and mode of uptake in a subterranean mammal, the Damara mole-rat. Journal of Nutrition 122, 108-114.

Reinhardt, T. A., Horst, R. L., Orf, J. W. \& Hollis, B. W. (1984). A microassay for 1,25-dihydroxyvitamin D not requiring high performance liquid chromatography: application to clinical studies. Journal of Clinical Endocrinology and Metabolism 58, 91-98.

Schaafsma, G., Duursma, S. A., Visser, W. J. \& Dekker, P. R. (1985). The influence of dietary calcium on kidney calcification and renal function in rats fed high-phosphate diets. Bone 6, 155-163.

Schryver, H. F., Craig, P. H., Hintz, H. F., Hogue, D. E. \& Lowe, J. E. (1970). The site of calcium absorption in the horse. Journal of Nutrition 100, 1127-1132.

Shore, R. F., Hayes, M. E., Balment, R. J. \& Mawer, E. B. (1988). Serum $25(\mathrm{OH}) \mathrm{D}_{3}$ and $1,25(\mathrm{OH})_{2} \mathrm{D}_{3}$ levels in wild and laboratory-bred wood mice and bank voles. In Vitamin D. Molecular, Cellular and Clinical Endocrinology, pp. 633-634 [A. W. Norman, K. Schaefer, H. G. Grigoleit and D. von Herrath, editors]. Berlin, Germany: Walter de Gruyter \& Co.

Silverberg, S. J. (1990). The distribution and balance of calcium, magnesium and phosphorus. In: Primer on the Metabolic Bone Diseases and Disorders of Mineral Metabolism, pp. 30-32 [M. J. Favus, editor]. Kelseyville, California: American Society of Bone and Mineral Research.

Skinner, D., Moodley, G. \& Buffenstein, R. (1991). Is vitamin $D_{3}$ essential for mineral metabolism in the Damara mole-rat (Cryptomys damarensis)? General and Comparative Endocrinology 81, 500-505.

Thomas, M. L., Ibarra, M. J., Solcher, B., Wetzel, S. \& Simmons, D. J. (1988). Effects of 25-hydroxyvitamin $D_{z}$ on rat duodenum, jejunum and ileum. Correlation of calcium active transport with tissue levels of vitamin $D_{3}$ metabolites. Journal of Biological Chemistry 249, 1156-1161.

Turnbull, H., Trafford, D. J. H. \& Mailen, H. L. K. (1982). A rapid and simple method for the measurement of plasma $25-\mathrm{OH}-\mathrm{D}_{2}$ and $25-\mathrm{OH}-\mathrm{D}_{3}$ using sep-pac $\mathrm{C}_{18}$ cartridges and a single high performance liquid chromatography step. Clinica Chimica Acta 120, 65-76.

Walling, M. W., Favus, M. J. \& Kimberg, D. V. (1974). The effect of low dietary calcium and calcium supplementation on calcium metabolism and bone in the immature, growing rat. Bone and Mineral 4, $73-82$.

Wilson, T. H. \& Wiseman, G. (1954). The use of the everted small intestine for the study of the transference of substances from the mucosal to the serosal surface. Journal of Physiology (London) 123, 116-125.

Zar, J. H. (1974). Biostatistical Analysis. London: Prentice-Hall. 